\title{
Taste acuity in response to zinc supplementation in older Europeans
}

\author{
Barbara J. Stewart-Knox ${ }^{1}$, Ellen E.A. Simpson ${ }^{1,2}$, Heather Parr $^{1}$, Gordon Rae ${ }^{2}$, Angela Polito ${ }^{3}$,
} Federica Intorre ${ }^{3}$, Maud Andriollo Sanchez ${ }^{4}$, Natalie Meunier ${ }^{5}$, Jacqueline M. O'Connor ${ }^{1}$, Giuseppe Maiani ${ }^{3}$, Charles Coudray ${ }^{5}$ and J. J. Strain ${ }^{1}$

${ }^{1}$ Northern Ireland Centre for Food and Health, University of Ulster, Coleraine BT52 1SA, UK

${ }^{2}$ School of Psychology, University of Ulster, Coleraine, $U K$

${ }^{3}$ National Institute for Food and Nutrition Research, INRAN, Rome, Italy

${ }^{4}$ Laboratoire de Nutrition Vieillissement et Maladies Cardiovasculaires (NVMC), Faculté de Pharmacie,

Université de Joseph Fourier, Grenoble, France

${ }^{5}$ Centre de Recherche en Nutrition Humaine d'Auvergne, Unité des Maladies Métaboliques et Micronutrients, INRA,

Clermont-Ferrand/Theix, France

(Received 5 September 2006 - Revised 29 May 2007 - Accepted 31 May 2007)

Taste acuity declines with age and may be dependent upon $\mathrm{Zn}$ status. The aim of the present double-blind, randomised controlled intervention trial

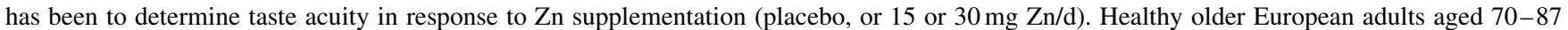
years were recruited within Italy (Rome) $(n$ 108) and France (Grenoble) ( $n$ 91) to the European Commission-funded Zenith project. A signal detection theory approach was adopted for taste assessment. The data were converted to R indices and analysed by repeated-measures ANOVA controlling for baseline taste acuity as well as serum and erythrocyte $\mathrm{Zn}$. Serum Zn increased post-intervention, indicating compliance with the intervention. Results differed across geographical region. Salt taste acuity was greater in response to $\mathrm{Zn}(30 \mathrm{mg})$ than placebo post-intervention among those recruited in Grenoble. There was no apparent change in acuity for sweet, sour or bitter taste in response to $\mathrm{Zn}$. Supplemented $\mathrm{Zn}$ may have potential to enhance salt taste acuity in those over the age of 70 years. Further research is required to determine if enhanced salt taste acuity is reflected in the eating experiences of older individuals.

Zinc: Elderly: Taste acuity: Signal detection: Basic tastes

Serum $\mathrm{Zn}$ levels tend to decrease with advancing age ${ }^{1,2}$, possibly because of lower consumption of Zn-rich foods, or foods that adversely affect the bioavailability of $\mathrm{Zn}$, by older individuals $s^{3,4}$. Taste acuity also appears to decline in normal ageing $^{5-8}$. Previous taste threshold studies have indicated that the extent of decline in taste acuity differs for each of the basic tastes. Consistent evidence implies an age-related decline in salt taste acuity ${ }^{6,8-10}$, which may be associated with putative indicators of $\mathrm{Zn}$ status ${ }^{11}$. $\mathrm{Zn}$ is present in saliva $^{12}$ as well as in the salivary gland ${ }^{13}$ and is linked to gustatory nerve activity ${ }^{14}$. $\mathrm{Zn}$ is bound to gustin, which is a protein and, like $\mathrm{Zn}$, a component of saliva ${ }^{15}$. Zn deficiency can be associated with a lack of gustin ${ }^{16}$ and can potentially lead to impaired taste acuity ${ }^{7}$. $\mathrm{Zn}$ may be involved in the control of appetite through interaction with leptin ${ }^{17}$. Depleted $\mathrm{Zn}$ can be associated with reduced appetite generally and may result from, or lead to, decreased intake of Zn-rich foods by older individuals ${ }^{2,18-20}$. Zn deficiency, therefore, could be both a cause and an effect of age-related decline in taste acuity.

Taste impairment has been observed in cases of $\mathrm{Zn}$ deficiency ${ }^{21,22}$ and supplemental $\mathrm{Zn}$ has been shown to both prevent $^{23}$ and treat ${ }^{24}$ taste disorder and enhance taste acuity in $\mathrm{Zn}$-depleted individuals ${ }^{25-27}$. It is important to consider the degree to which age-impaired taste acuity is responsive to $\mathrm{Zn}$ supplementation given the potentially detrimental effect upon food preference and choice and, ultimately, overall dietary quality ${ }^{28,29}$. Older individuals are at risk of sub-optimal $\mathrm{Zn}$ intake for physiological, psychosocial and economic reasons ${ }^{30}$. Age-related decline in taste acuity, therefore, could potentially result from failure to meet $\mathrm{Zn}$ requirement. There is convincing evidence that would lead us to assume that a large proportion of individuals over the age of 60 years experience some degree of age-related decline in taste acuity $^{31-33}$. The present study, therefore, meets a need to establish whether supplemental $\mathrm{Zn}$ can improve taste acuity in normal ageing 9 . The aim of the present double-blind, randomised controlled intervention trial was to compare taste acuity for the four basic tastes (sweet, sour, bitter and salt) using a signal detection approach, in response to elemental $\mathrm{Zn}$ supplementation (placebo, or $15 \mathrm{mg}$ or $30 \mathrm{mg} \mathrm{Zn} / \mathrm{d}$ ) in healthy older European adults aged 70-87 years recruited in Grenoble (France) and Rome (Italy). 


\section{Methods}

The research was carried out from centres in Grenoble (University de Joseph Fourier) and Rome (Istituto Nazionale di Ricerca per gli Alimenti e la Nutrizione; INRAN). Ethical approval was obtained independently by both research centres to conduct the present study. All volunteers gave informed written consent to take part in the screening and research study. A randomised, placebo-controlled, doubleblind clinical controlled trial design was employed in which taste acuity (detection thresholds) for the four basic tastes was assessed in response to elemental $\mathrm{Zn} \mathrm{(15 \textrm {mg }}$ and $30 \mathrm{mg}$ ) or placebo over a 6-month period. Because the present study aimed to determine the impact of $\mathrm{Zn}$ upon healthy ageing, it was necessary to employ dosages that would not be toxic to healthy individuals and available without prescription.

\section{Sampling}

Older individuals were recruited through community groups and organisations. Prospective volunteers then initiated contact with the research group. Approximately $10-15 \%$ of those initially approached through leaflets, community groups, etc volunteered to take part in the study. Volunteers underwent screening provided they met none of the following exclusion criteria: undergoing treatment for acute or chronic disease (including cancer, diabetes, renal or hepatic disease, malabsorption and chronic inflammatory pathologies); having a BMI of $<20$ and $>33 \mathrm{~kg} / \mathrm{m}^{2}$; consuming a special prescribed diet or having unusual dietary habits (vegetarian or vegan); consuming $>30 \mathrm{~g}$ alcohol/d (more than twenty-one units/week) for men or $>20 \mathrm{~g}$ alcohol/d (more than fourteen units/week) for women; smoking more than ten cigarettes per $\mathrm{d}(>10 \mathrm{~g}$ tobacco/d); taking more than four prescription drugs; using hormone replacement therapy; taking medication that could affect $\mathrm{Zn}$ absorption; taking nutritional supplements containing minerals or trace elements within 6 months of commencement of the study $^{34}$. Zn at doses of $30 \mathrm{mg}$ and above can be toxic, especially if $\mathrm{Cu}$ intake is sub-optimal ${ }^{35,36}$. Individuals with chronic intestinal disorders and any who were prescribed medication, nutritional supplements or dietary regimes that could affect $\mathrm{Zn}$ absorption or inhibit $\mathrm{Zn}$ bioavailability were also excluded from taking part in the study. Full medical screening was provided which included liver and kidney function tests, full blood profiles, and blood pressure and heart rate measures. Qualified phlebotomists and nurses took blood for these tests. Volunteers were assessed for depression by means of the Geriatric Depression Scale ${ }^{37}$ and for dementia by means of the Mini Mental State Examination $^{38}$. Those with cognitive deficit or mental health problems were subsequently excluded from the study. There was some sample attrition subsequent to recruitment (n 23). This was because a number of volunteers did not arrive for initial testing, while others refused supplementation. The eventual sample subjects were apparently healthy community-dwelling older adults aged $70-87$ years ( $n$ 199). Approximately equal numbers of males and females were randomly allocated to either the placebo, or $15 \mathrm{mg}$ or $30 \mathrm{mg} \mathrm{Zn}$-supplemented groups.

\section{Putative indicators of zinc status}

Both serum and erythrocyte $\mathrm{Zn}$ determinations were carried out at the Laboratoire Nutrition, Vieillissement et Maladies Cardiovasculaires (NVMC), Grenoble, France. Details of sample storage and transport have been reported elsewhere by Andriollo-Sanchez et al. ${ }^{39}$. Serum, erythrocyte and urinary $\mathrm{Zn}$ concentrations were determined by flame atomic absorption spectrometry using a PerkinElmer 560 (PerkinElmer Life And Analytical Sciences, Inc., Waltham, MA, USA) and employing a previously described method ${ }^{40}$. Seronorm ${ }^{\circledR}$ trace element serum was used as an internal quality control (Sero ${ }^{\circledR}$, Billingstad, Norway). Dietary Zn intake was assessed by means of a semi-structured standardised $4 \mathrm{~d}$ food diary. The information in the food diaries was analysed using the NetWISP (version 3.0; Tinuviel Software, Anglesey, UK) database.

\section{Taste threshold assessment}

Taste acuity refers to the range of taste stimuli that an individual is able to detect ${ }^{41}$ and is usually assumed from taste threshold assessment. Taste acuity is reflected in ability to detect and/or recognise the four to five basic tastes sweet, sour, salty, bitter, and umami (monosodium glutamate) - and can be assessed in a variety of different ways ${ }^{42}$. The reported study adopts a signal detection theory approach ${ }^{43}$ adapted for sensory taste threshold measurement ${ }^{44}$ for which it has been shown to produce repeatable results ${ }^{45}$. Signal detection theory views sensory taste threshold detection as the outcome of a cognitive decision-making process ${ }^{46}$. The procedure adopted required the panellist to decide whether 'noise' (i.e. water) or 'noise and signal' (i.e. water and tastant) was present in each trial comprised of three samples (one signal and two noise stimuli) ${ }^{47}$. As a measure of decision criteria and to control for guessing, panellists were also required to indicate whether they were sure or unsure of their decision.

\section{Test stimuli}

The taste solutions were made up using glucose (sweet), sodium chloride (salt), citric acid (sour) and quinine hydrochloride (bitter). Both research centres acquired equipment and ingredients for the taste solutions from the same suppliers. All chemicals were 'food' grade. Sodium chloride and glucose were both supplied by Provincial Butchers Supplies Ltd (Lisburn, County Antrim, UK). Sigma Aldrich, UK, supplied the citric acid and quinine hydrochloride. Each tastant was suspended in a series of six solutions of increasing concentration using ultra-purified water (deionisation and reverse osmosis to purity greater than $15 \mathrm{M} \Omega$ ). With exception of glucose, these initial solutions were based on concentrations previously presented to older adults and reported by Mojet et al. ${ }^{6}$. A pilot study ( $n$ 4) employing three females and one male, aged over 55 years, was carried out to establish that the range of strengths required for each basic taste was adequate to prevent ceiling or floor effects. This resulted in the final ranges $(\mathrm{g} / \mathrm{l})$ : sweet (glucose), $4 \times 10^{-1}-51$; sour (citric acid), $1 \times 10^{-3}-39 \times 10^{-2}$; salty (sodium chloride), $6 \times 10^{-3}-1.75$; bitter (quinine hydrochloride), $1 \times 10^{-4}-7.5 \times 10^{-2}$. 
The solutions were prepared weekly. For each taste concentration, the compounds were weighed out, added to $800 \mathrm{ml}$ purified water in a Pyrex beaker, stirred until dissolved, then poured into a volumetric 1 litre flask, to which further purified water was added to make up 1 litre of the solution and then stirred well. Solutions were stored at $5^{\circ} \mathrm{C}$ for use within 3-4d. Polypropylene cups were used to contain each tastant and/or purified water, the volume of which presented was $2.5 \mathrm{ml}$. The solutions were then presented at room temperature for the purpose of the sensory trials.

\section{Procedure}

The intervention commenced in February 2003 and completed in September 2004. Subsequent to a $12 \mathrm{~h}$ overnight fast, blood samples $(5 \mathrm{ml})$ for serum and erythrocyte $\mathrm{Zn}$ assay were collected via antecubital venepuncture into EDTA and serum tubes by a qualified phlebotomist at baseline and again 3 months and 6 months into the intervention period. For $\mathrm{Zn}$ status determination, blood was collected using trace element-free vacutainer ${ }^{\circledR}$ tubes (Becton Dickinson, Le Pont de Claix, France). Samples were kept on ice immediately after drawing. Trace element-free pipettes and vials were also used for the preparation of samples. Fasting venous blood samples were allowed to sit at room temperature and clot for $30 \mathrm{~min}$ before serum was separated from blood cells by centrifugation $(15 \mathrm{~min} ; 1000 \mathrm{~g})$ and then sampled into Eppendorfs. EDTA tubes were centrifuged immediately at $1500 \mathrm{rpm}$ for $15 \mathrm{~min}$ and then sampled into Eppendorfs. Erythrocytes were then washed three times in PBS (pH 7.4). Serum samples were diluted $1: 5$ in $0.1 \mathrm{M}-\mathrm{HCl}$. Erythrocytes were diluted 1:100 in deionised water. Serum and erythrocytes were stored at $-80^{\circ} \mathrm{C}$. Carriage conditions for the frozen samples were identical across the two regions.

Dietary $\mathrm{Zn}$ was assessed at baseline and 6 months later at the conclusion of the intervention using $4 \mathrm{~d}$ food diaries that included estimates of portion size. Full standardised written and verbal instructions were provided. All food and drink consumed, including snacks, was recorded in the food diary over 4 consecutive days comprising two weekdays (Thursday and Friday) and two weekend days (Saturday and Sunday).

Participants were required to take elemental $\mathrm{Zn}$ (either 15 or $30 \mathrm{mg}$ ) per d (as zinc gluconate) or placebo over a period of 6 months. Supplements were supplied by E-Pharma and issued in $7 \mathrm{~d}$ pill organiser boxes (Carepac, Farringdon, Oxon, UK). The study required that all participants ingested two tablets daily. Those in the $15 \mathrm{mg} \mathrm{Zn}$ group received two capsules of $7.5 \mathrm{mg}$ daily and those in the $30 \mathrm{mg} \mathrm{Zn}$ group received two $15 \mathrm{mg}$ capsules daily. Written instructions as to when and how to take the tablets were provided. The pill-boxes were checked for compliance and replenished every 6 weeks. Participants also kept a diary to record any supplements that they forgot to take.

Taste acuity (threshold) assessment also took place initially at baseline and was repeated at 3 and 6 months during the intervention period. Both centres carried out tasting at the same time of day, in the early morning (09.00 hours) and employed the same method throughout. Participants were asked to attend the food sensory testing laboratory early in the morning having fasted overnight to control for individual differences in satiety.
The order in which the basic tastes were presented was standardised as follows: citric acid (sour); glucose (sweet); sodium chloride (salt); quinine (bitter). Both verbal and written standardised instructions were given on how to carry out the test. The aqueous solutions $(2.5 \mathrm{ml})$ were presented in the cups on a tray in six ascending concentrations for each taste quality. For each basic taste, eighteen cups were set out in six rows each of three cups, one cup per row contained the taste solution (signal plus noise) and the other two cups contained purified water (noise). A comparison of results of 'sip and spit' and 'sip and swallow' tests have indicated that sip and spit tests do not relate well to consumption ${ }^{48}$. This suggests that results of sip and spit tests should be interpreted with caution especially when assessments have been made by untrained panellists. Accordingly, 'natural' consumptionbased tasting methods were deemed appropriate for the present study. In an effort to mimic normal taste conditions as far as possible and in doing so to maximise the chances that the taste be detected, participants were instructed to 'sip and swallow' each solution 'in their normal way'.

Participants were instructed to sample, in an ascending series, the contents of each of the three cups $(2.5 \mathrm{ml}$ in each cup) in each row once, decide which solution was different and to record their decision on a standardised response sheet before moving on to taste the next row containing solutions of greater strength. The task was to distinguish the 'signal' (tastant plus purified water) from the 'noise' (purified water) in each row. In addition, for each row (triad) the participants were required to indicate whether they were sure or unsure as to their decision. No rinsing was advocated between taste samples, merely to sip and swallow purified water following presentation of each taste (sour, sweet, salt and bitter) and before moving on to the next, to minimise habituation to the different taste qualities. No conferring on decisions was permitted. On completion of the research study, a light breakfast was provided.

\section{Data analysis}

The $\mathrm{R}$ index is a data-handling technique developed by Brown $^{49}$ for the purpose of discrimination studies and is amenable to parametric analysis ${ }^{44}$. The $\mathrm{R}$ index is the predicted probability of the correct choice of a signal over noise $\mathrm{e}^{50}$ taking into account individual differences in decision-making criteria. For the purpose of the present study, the $\mathrm{R}$ index was derived from the information recorded during signal detection trials regarding the detection of a signal or noise also taking into account whether the respondent was sure or unsure about each decision. Each response was quantified and tabulated into one of the following categories: correct-signal-sure; correct-noise-sure; correct-signal-unsure; correct-noise-unsure; incorrect-signal-sure; incorrect-noisesure; incorrect-signal-unsure; incorrect-noise-unsure. Data were then converted to $\mathrm{R}$ indices using a macro statistical equation created in Microsoft Excel (Microsoft Corp., Redmond, WA, USA). The higher the $\mathrm{R}$ index the lower the taste threshold and the greater the taste acuity. $\mathrm{R}$ indices were computed for citric acid, glucose, salt and quinine and were entered separately as dependent variables in each analysis. Data were then transferred into Statistical Package for the Social Sciences (version 11; SPSS Inc., Chicago, IL, USA). 
Factorial ANOVA was carried out to determine any change in serum and erythrocyte $\mathrm{Zn}$ levels in response to the $\mathrm{Zn}$ intervention (placebo, or $15 \mathrm{mg}$ or $30 \mathrm{mg} \mathrm{Zn}$ ). Repeated-measures ANOVA was undertaken to compare dietary $\mathrm{Zn}$ and salt intake between centres (Rome and Grenoble) and by condition (placebo, or $15 \mathrm{mg}$ or $30 \mathrm{mg} \mathrm{Zn}$ ) over time (baseline and 6 months). Factorial ANOVA with repeated measures (baseline, 3 months and 6 months) was carried out separately for each region (Rome and Grenoble) and for each basic taste (sweet, sour, salt and bitter) to establish differences in taste acuity in response to $\mathrm{Zn}$ (placebo, or $15 \mathrm{mg}$ or $30 \mathrm{mg} \mathrm{Zn}$ ). Baseline serum and erythrocyte $\mathrm{Zn}$ status values were entered as covariates to control for differences in $\mathrm{Zn}$ status before intervention. Baseline taste acuity was also entered into the analysis as a covariate to control for individual differences in taste acuity.

\section{Results}

\section{Sample description}

Approximately equivalent proportions of each sex were recruited in Rome, Italy (fifty-six males and fifty-two females; mean age 74.5 years) and Grenoble, France (forty-seven males and forty-four females; mean age 74.2 years). A total of 189 individuals (ninety-one in Grenoble and ninety-eight in Rome) completed the taste tests. Owing to difficulties in classifying social class by occupation across cultures, social class has been collapsed into three groupings (professional, skilled and unskilled). Grenoble had a higher proportion of professional participants $(41 \%)$ than Rome (27\%). Educational background was evaluated in terms of the percentage that completed tertiary education in Rome (20\%) and Grenoble (15\%).

\section{Putative indicators of zinc status}

There were no differences in serum $\mathrm{Zn}$ between regions or treatment group at baseline. Mean serum $\mathrm{Zn}$ levels were within the normal range $(11-18 \mu \mathrm{mol} / \mathrm{l})^{39}$ for the placebo (13.20 (sD 1.69) $\mu \mathrm{mol} / \mathrm{l}), 15 \mathrm{mg}$ (13.28 (SD 1.84) $\mu \mathrm{mol} / \mathrm{l}$ ) and $30 \mathrm{mg}(13.13$ (SD 1.63) $\mu \mathrm{mol} / \mathrm{l})$ supplemented groups at baseline and remained so throughout the intervention period. Serum Zn increased post-intervention $\left(F_{(4,197)}=11.021\right.$; $P=0.000)$ in both the $15 \mathrm{mg}(13.99 \quad(\mathrm{SD} \mathrm{2.47)} \mu \mathrm{mol} / \mathrm{l}$; $P=0.018)$ and $30 \mathrm{mg}(15.03$ (SD 3.17) $\mu \mathrm{mol} / \mathrm{l} ; P=0.000)$ supplemented groups compared with placebo (13.05 (SD 1.66) $\mu \mathrm{mol} / \mathrm{l}$ ) (Fig. 1). Serum $\mathrm{Zn}$ levels in response to $30 \mathrm{mg} \mathrm{Zn}$ were higher among those recruited in Rome (16.26 (SD 3.41) $\mu \mathrm{mol} / \mathrm{l})$ than Grenoble (13.64 (SD 2.21) $\mu \mathrm{mol} / \mathrm{l})$ post-intervention $\left(F_{(4,197)}=3 \cdot 526 ; P=0.008\right)$.

\section{Dietary assessment}

Dietary $\mathrm{Zn}$ intake decreased between baseline (12.33 (SE $0.528) \mathrm{mg} / \mathrm{d}$ ) and 6 months (10.52 (SE 0.349$) \mathrm{mg} / \mathrm{d})$ among those in Grenoble $\left(F_{(1,186)}=4.196 ; \quad P=0.042\right)$ but not Rome. Na intake was higher among those in Grenoble (2433.50 (SE 61.07) g/d) than in Rome (1285.22 (SE 55.73) $\mathrm{g} / \mathrm{d})$ at both baseline and 6 months $\left(F_{(1,186)}=192 \cdot 874\right.$; $P=0.000)$. There were no differences in $\mathrm{Zn}$ or $\mathrm{Na}$ intake between treatment groups at either centre.

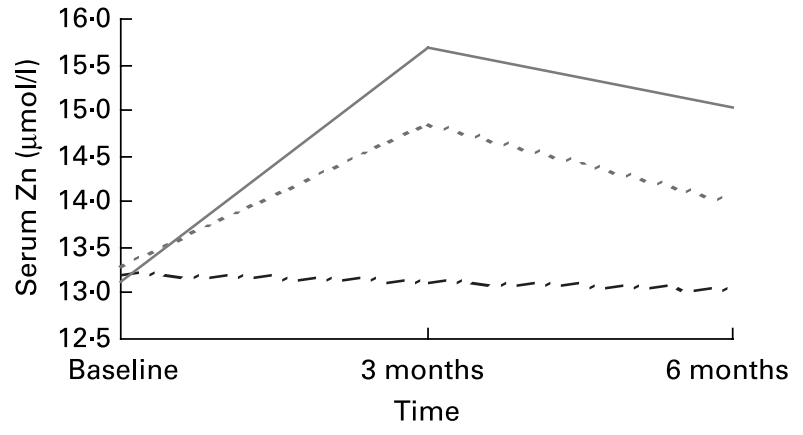

Fig. 1. Serum $\mathrm{Zn}$ in response to $\mathrm{Zn}$ supplementation in older adults (70-87 years) from Rome and Grenoble ( $n$ 197). (-..), Placebo; (....), $15 \mathrm{mg} \mathrm{Zn;}$ $(-), 30 \mathrm{mg}$ zinc. Values are means.

Mean erythrocyte $\mathrm{Zn}$ levels were also within normal limits $(120-250 \mu \mathrm{mol} / \mathrm{l})$ at baseline and remained normal throughout the intervention period. The sample recruited in Grenoble (188.54 (SD 49.38) $\mu \mathrm{mol} / \mathrm{l})$ had lower erythrocyte $\mathrm{Zn}$ levels than those in Rome at baseline (213.79 (SD 60.28) $\mu \mathrm{mol} / \mathrm{l}$ ) $\left(F_{(2,189)}=15 \cdot 579 ; P=0 \cdot 000\right)$. Erythrocyte $\mathrm{Zn}$ did not alter in either sample (Rome or Grenoble) in response to the intervention.

\section{Zinc and taste acuity}

Acuity for salt taste was greater in the $30 \mathrm{mg}$ supplemented group (0.84 409 (SD 0.13349)) than the placebo group $(0.75045$ (SD 0.210)) post-intervention in the Grenoble sample $\left(F_{(2,91)}=3.632 ; P=0.031\right)$ (Fig. 2). There were no apparent differences in taste acuity in response to the $30 \mathrm{mg} \mathrm{Zn}$ intervention for sweet, sour or bitter tastes among those recruited in Grenoble or for any of the four basic tastes in the Rome sample. There were no apparent differences in acuity for any of the tastes in response to $15 \mathrm{mg} \mathrm{Zn}$.

\section{Discussion}

Salt taste acuity increased in response to $30 \mathrm{mg} \mathrm{Zn}$ in older adults recruited in Grenoble. Many factors may influence salt taste acuity. Sensory threshold for salty tastes can

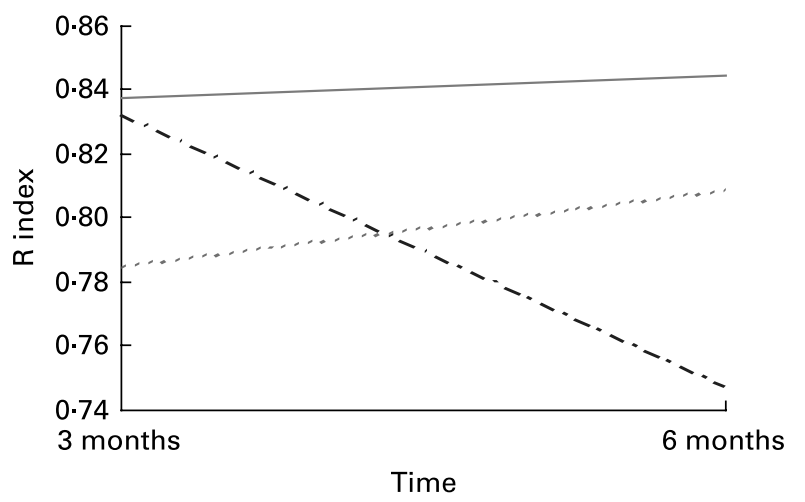

Fig. 2. Salt taste acuity in response to $\mathrm{Zn}$ supplementation in older adults (70-87 years) from Grenoble ( $n$ 91). (-..), Placebo; ( $\ldots \ldots)$, $15 \mathrm{mg} \mathrm{Zn;}(-)$, $30 \mathrm{mg}$ zinc. Values are means. Baseline taste acuity was entered into the analysis as a covariate. 
become elevated with age $\mathrm{e}^{6-8,10,41}$. That $\mathrm{Zn}$ enhanced salt taste acuity was, therefore, not surprising. The finding that salt taste acuity increased in response to $\mathrm{Zn}$ among those recruited in Grenoble but not in Rome is more difficult to explain. Although mean erythrocyte $\mathrm{Zn}$ was within normal limits in both groups throughout the study, participants recruited in Grenoble, on average, had lower levels of erythrocyte $\mathrm{Zn}$ than those in Rome at baseline. This apparent baseline difference in long-term putative erythrocyte $\mathrm{Zn}$ status could explain why salt taste acuity improved subsequent to $30 \mathrm{mg} \mathrm{Zn}$ among those in Grenoble but not Rome. Given that differences in putative measures of $\mathrm{Zn}$ status (serum and erythrocyte $\mathrm{Zn}$ ) and taste acuity at baseline were controlled for in the analysis, however, suggests that this baseline difference in long-term putative $\mathrm{Zn}$ status was unlikely to have influenced the findings.

Differences in reported $\mathrm{Zn}$ and $\mathrm{Na}$ intake between those recruited in Grenoble and Rome may provide clues as to the disparate response of the two centres to the $\mathrm{Zn}$ intervention. Reported dietary $\mathrm{Zn}$ intake decreased between baseline and 6 months into the intervention among those recruited in Grenoble but not Rome. That a similar reduction in dietary $\mathrm{Zn}$ intake occurred between baseline and 6 months in the placebo and the treatment groups, however, suggests that the decrease in reported dietary $\mathrm{Zn}$ was not a response to the $\mathrm{Zn}$ supplementation and may reflect seasonal variation in dietary habits. Whether the apparent decrease in $\mathrm{Zn}$ intake over the intervention period among those in Grenoble was enough to bring about the improvement in salt taste acuity observed exclusively in this sample is a matter for further study.

Sodium intake was reportedly higher among those in Grenoble than in Rome. Previous research has suggested that higher dietary $\mathrm{Zn}$ intake is associated with better taste acuity for salt because $\mathrm{Na}$ and $\mathrm{Zn}$ intake are related ${ }^{51}$. It is unfortunately difficult to draw firm conclusions on the basis of food records. Not only are diaries subject to reporting bias ${ }^{52-54}$ but dietary information gathered over $4 \mathrm{~d}$ may not be representative of habitual intakes ${ }^{55}$. Na intake is especially difficult to assess with any degree of accuracy ${ }^{56,57}$. Improved salt taste acuity in response to the $\mathrm{Zn}$ intervention among those in Grenoble could, nevertheless, be associated with higher $\mathrm{Zn}$ and $\mathrm{Na}$ intake reported at baseline by this group.

Inadequate $\mathrm{Zn}$ intake and potentially $\mathrm{Zn}$ status is more common among socio-economically deprived groups ${ }^{58,59}$. The apparent improvement in taste acuity subsequent to intervention with $\mathrm{Zn}(30 \mathrm{mg})$ in Grenoble but not Rome cannot, however, easily be explained by socio-demographic-related differences in $\mathrm{Zn}$ status between the two groups. The two samples recruited to the present study, although derived from different European regions, were proportionally similar in terms of age, sex and only marginally different in terms of education and social class. The finding that supplemented $\mathrm{Zn}$ only benefited salt taste acuity among those in Grenoble and not Rome, therefore, provides further evidence to imply that differences in taste response to $\mathrm{Zn}$ were to some degree dependent upon culturally determined differences in dietary habits between the two countries ${ }^{60}$ and, accordingly, taste response to $\mathrm{Zn}$. Future research should consider culturally determined lifestyle differences including dietary $\mathrm{Zn}$ intake in relation to taste acuity, putative measures of $\mathrm{Zn}$ status and response to $\mathrm{Zn}$ supplementation.
Serum $\mathrm{Zn}$, as expected, increased in the treated groups over the course of the study, indicating good compliance with the intervention. Erythrocyte $\mathrm{Zn}$, however, did not increase in either group during the intervention period. Expressing erythrocyte $\mathrm{Zn}$ concentrations in absolute values rather than in terms of $\mu \mathrm{g}$ per $\mathrm{g} \mathrm{Hb}$ increased the possibility that any rise in erythrocyte $\mathrm{Zn}$ levels in response to the intervention could have been missed if changes in the $\mathrm{Hb}$ content of the blood samples occurred between baseline and 6 months of supplementation. Unfortunately, no interpretative criteria for erythrocyte $\mathrm{Zn}$ have been established and there are no standardised units for the expression of $\mathrm{Zn}$ concentration in erythrocytes, making any comparison between different methods and studies difficult.

Another limitation of the present study is that, on the basis of the biochemical measures taken (serum, erythrocyte and dietary $\mathrm{Zn}$ ), it has not been possible to establish conclusively that the participants in the present study were $\mathrm{Zn}$ replete. Various methods are available to assess $\mathrm{Zn}$ status. Diagnosis of $\mathrm{Zn}$ deficiency, nevertheless, is hampered by the lack of a single, specific and sensitive biochemical index that reflects the entire spectrum of $\mathrm{Zn}$ status from deficiency through adequacy to excess and toxicity. Besides serum and erythrocyte $\mathrm{Zn}$, leucocyte, neutrophil, urine, hair and salivary Zn levels could have been assessed, none of which have proven useful in identifying marginal $\mathrm{Zn}$ deficiency in $\operatorname{man}^{16,61}$. Given the lack of a single valid biochemical measure of $\mathrm{Zn}$ status ${ }^{62}$ we cannot establish conclusively that the participants in the present study were $\mathrm{Zn}$ replete.

The dietary records indicate that the subjects in the study group were $\mathrm{Zn}$ replete. Reported mean daily dietary $\mathrm{Zn}$ intake in our sample of older adults was estimated at 10.53 (SD 5.24) $\mathrm{mg} / \mathrm{d}$ for females and 12.04 (SD 5.01) $\mathrm{mg} / \mathrm{d}$ for males ${ }^{39}$. Recommended daily intake for $\mathrm{Zn}$ varies between countries. Based on the Nutrition Board and Institute of Medicine $^{63}$ figures $(8 \mathrm{mg} / \mathrm{d}$ for females and $11 \mathrm{mg} / \mathrm{d}$ for males), according to $4 \mathrm{~d}$ food diaries, the proportion of those recruited to the present study who were consuming below two-thirds of the RDA for $\mathrm{Zn}$ was small $(0 \%$ of females and $3.55 \%$ of males $)^{39}$. These dietary $\mathrm{Zn}$ intake levels appear higher than those reported in other studies, for example, 10.9 (SD 0.21) $\mathrm{mg} / \mathrm{d}$ for men and 7.8 (SD 0.14) $\mathrm{mg} / \mathrm{d}$ for women in the Third National Health and Nutrition Examination Survey (NHANES III) population aged $>60$ years $^{64}$, 12 (SD 6.4) $\mathrm{mg} / \mathrm{d}$ for males and 8.0 (SD 4.0) $\mathrm{mg} / \mathrm{d}$ for females observed in the Continuing Survey of Food Intakes by Individuals (CSFII) study of those aged $60+{ }^{59}$ and $8.4 \mathrm{mg} / \mathrm{d}$ for the Iowa $65+$ Rural Health Study (IRHS) ${ }^{65}$. The $4 \mathrm{~d}$ dietary intake records indicate that our sample of healthy older adults were dietary $\mathrm{Zn}$ replete.

Assuming that the sample was healthy and dietary $\mathrm{Zn}$ replete and in view of the negative finding in response to $15 \mathrm{mgZn}$, it could be argued that the observed effect for $30 \mathrm{mg} \mathrm{Zn}$ was pharmacological rather than nutritional. The highest daily nutrient intake level likely to pose no risk of adverse health effects for adults is $25 \mathrm{mg} / \mathrm{d}$, including dietary and supplemental $\mathrm{Zn}^{66}$. It has been suggested that higher than recommended doses of $\mathrm{Zn}$ supplemented over prolonged periods can induce toxicity by inhibiting $\mathrm{Cu}$ bioavailability $^{58,67}$. Other research involving postmenopausal women, however, has suggested that inadequate intake of $\mathrm{Zn}$ is more 
likely than high intake of $\mathrm{Zn}$ to be associated with decreased $\mathrm{Cu}$ status ${ }^{35}$. In view of this, it was not surprising that putative indices of $\mathrm{Cu}$ status did not appear to alter in response to $\mathrm{Zn}$ intervention in the healthy older adults recruited to the present study ${ }^{68}$, suggesting that it was unlikely that they experienced toxic effects as a consequence of any decrease in $\mathrm{Cu}$ status as a result of the $\mathrm{Zn}$ intervention.

The present study is unusual in having explored taste acuity in response to $\mathrm{Zn}$ in a healthy, apparently Zn-replete, group of older individuals. Most previous studies that have observed an improvement in taste acuity in response to supplemented $\mathrm{Zn}$ have tended to employ a small number of $\mathrm{Zn}$-depleted individuals derived from clinical populations ${ }^{23-25,27,69}$. The present research is also novel in that it has investigated the impact of $\mathrm{Zn}$ supplementation upon taste acuity in doses that reflect recommended daily amounts. Other studies have tended to intervene with higher doses than the 15 and $30 \mathrm{mg} \mathrm{Zn}$ used for the purpose of the present study. Sweet, sour and bitter taste thresholds have been apparently enhanced subsequent to $45 \mathrm{mg}$ zinc sulfate ${ }^{27}$ and all four basic tastes observed to improve in response to $66 \mathrm{mg}^{69}$ and $140 \mathrm{mg}$ zinc sulfate per $\mathrm{d}^{25}$. Although the present research study investigated the impact of lower doses of $\mathrm{Zn}$ upon taste acuity in healthy ageing, making it difficult to compare findings across studies, these findings agree with those of previous studies using higher doses in clinical populations ${ }^{25,27,69}$ in suggesting that $\mathrm{Zn}$ is beneficial to taste acuity in doses of $30 \mathrm{mg}$ or above.

The specific protocol employed for the sensory testing in the present study is also different in some respects from that employed in other studies. Participants were instructed to sip and swallow rather than sip and spit the taste stimuli. Given that the panel were untrained, it was considered important that the solutions be tasted in the normal way, lending greater validity to the findings. Sip and spit would not have reflected 'normal' tasting conditions. The present study is also unusual in employing a signal detection approach to taste threshold assessment in older adults. Signal detection theory has been previously applied to the detection of salt ${ }^{45,50}$ in younger but not older individuals. Signal detection is perceived to be more robust than other sensory threshold techniques in that it enables individual differences in the way individuals make decisions to be taken into account. Signal detection theory could, therefore, be considered ideal for studies employing diverse samples. The use of the 'basic taste' paradigm to study taste acuity could also be perceived as controversial ${ }^{41}$. The method has nevertheless provided a well-controlled model that is replicable and which enables comparison across different studies and that appears to be particularly useful for clinical intervention trials looking at taste acuity in qualitatively different study populations.

\section{Conclusion}

The present study appears to be the first randomised clinical controlled intervention trial that has considered taste acuity in response to $\mathrm{Zn}$ supplementation in healthy ageing. Supplementation with $30 \mathrm{mg} \mathrm{Zn}$ may have potential to enhance salt taste acuity in those over the age of 70 years in certain cultures. Meanwhile, further research is required to determine if $\mathrm{Zn}$ supplementation, in improving salt taste acuity, can stimulate appetite or enhance the eating experience in older individuals. Although above the upper limit of $25 \mathrm{mg}, 30 \mathrm{mg}$ $\mathrm{Zn}$ is generally available to the consumer 'over the counter'; however, in view of potential adverse effects on $\mathrm{Cu}$ status of prolonged daily intake of $\mathrm{Zn}$, we should refrain from recommending such high doses to the consumer public.

\section{Acknowledgements}

ZENITH is supported by the European Commission 'Quality of Life and Management of Living Resources' Fifth Framework Programme, contract no. QLK1-CT-2001-00 168.

\section{References}

1. Maes M, deVos N, Wauters A, et al. (1999) Inflammatory markers in younger versus elderly normal volunteers. J Psychiat Res 33, 397-405.

2. Seiler WO, Itin P \& Stahelin HB (2002) Zinc deficiency, a problem of old age frequently not recognised. ErnahrungsUmschau 49, 260.

3. Cid-Ruzafa J, Caulfield LE, Barron Y \& West SK (1999) Nutrient intakes and adequacy among an older population the eastern shore of Maryland. J Am Diet Assoc 99, 546-571.

4. Kant AK \& Schatzkin A (1999) Relation of age and self reported chronic medical condition status with dietary nutrient intake in the US population. J Am Coll Nutr 18, 69-76.

5. Sanders OG, Ayers JV \& Oakes S (2002) Taste acuity in the elderly: the impact of threshold, age, gender, medication, health and dental problems. J Sensory Studies 17, 89-104.

6. Mojet J, Christ-Hazelhof E \& Heidema J (2001) Taste perception with age: generic or specific losses in threshold sensitivity to the five basic tastes. Chem Senses 26, 845-860.

7. Bales CW, Steinman LC, Freelandgraves JH, Stone JM \& Young RK (1986) The effect of age on plasma zinc uptake and taste acuity. Am J Clin Nutr 44, 664-669.

8. Bartoshuk LM, Rifkin B, Marks LE \& Bars P (1986) Taste and ageing. J Gerontol 41, 51-57.

9. Schiffman SS (1993) Perception of taste and smell in elderly persons. Crit Rev Food Sci Nutr 33, 17-26.

10. Murphy C (1993) Nutrition and chemosensory perception in the elderly. Crit Rev Food Sci Nutr 33, 3-15.

11. Stewart-Knox BJ, Simpson E, Parr H, et al. (2005) Zinc status and taste acuity in European older adults. Eur J Clin Nutr 59, Suppl. 2, S31-S36.

12. Watanabe M, Asatsuma M, Ikui A, Ikeda M, Yamada Y, Nomura S \& Igarashi A (2005) Measurements of several metallic elements and matrix metalloproteinases (MMP's) in saliva from patients with taste disorder. Chem Senses 30, $121-125$.

13. Tanaka M (2002) Secretory function of the salivary gland in patients with taste disorders or xerostomia: correlation with zinc deficiency. Acta Ota-Laryng 122, 134-141.

14. Yokoi K, Egger NG, Ramanujam VMS, Alcock NW, Dayal HH, Penland JG \& Sandstead HH (2003) Association between plasma zinc and zinc kinetic parameters in premenopausal women. Am J Physiol Endocrinol Metab 285, E1010-E1020.

15. Thatcher BJ, Doherty AE, Orvisky E, Martin BM \& Henkin RI (1998) Gustin from human parotid saliva is carbonic anhydrase VI. Biochem Biophys Res Comm 250, 635-641.

16. Pluhator MM, Thomson ABR \& Fedorak RN (1996) Clinical aspects of trace elements: zinc in human nutrition - assessment of zinc status. Canad J Gastroenterol 10, 37-42.

17. Konukoglu D, Turhan MS, Ercan M \& Serin O (2004) Relationship between plasma leptin and zinc levels and the effect of 
insulin and oxidative stress on leptin levels in obese diabetic patients. J Nutr Biochem 15, 757-760.

18. Shay NF \& Mangian HF (2000) Neurobiology of zinc-influenced eating behaviour. J Nutr 130, Suppl. 5S, 1493S-1499S.

19. Rolls B (1999) Do chemosensory changes influence food intake in the elderly? Physiol Behav 66, 193-197.

20. Little KY, Castellanos X, Humphries LL \& Austin J (1989) Altered $\mathrm{Zn}$ metabolism in mood disordered patients. Biol Psychiatry 26, 646-648.

21. Kettaneh A, Fain O, Stirnemann J \& Thomas M (2002) Taste disorders (article in French). Rev Med Interne 23, 622-631.

22. Tomita H \& Yoshikawa T (2002) Drug-related taste disturbances. Acta Ota-Laryng 122, 116-121.

23. Yamagata T, Nakamura Y, Yamagata Y, Nakanishi M, Matsunaga $\mathrm{K}$, Nakanishi $\mathrm{H}$, Nishimoto $\mathrm{T}$, Minakata $\mathrm{Y}$, Mune $\mathrm{M}$ \& Yikawa S (2003) The pilot trial of the prevention of the increase in electrical taste thresholds by zinc containing fluid infusion during chemotherapy to treat primary lung cancer. J Exp Clin Cancer Res 22, 557-563.

24. Stoll AL \& Oepen G (1994) Zinc salts for the treatment of olfactory and gustatory symptoms in psychiatric patients - a case series. J Clin Psychiatry 55, 309-311.

25. Heckmann SM, Hujoel P, Habiger S, Friess W, Wichmann M, Heckmann JG \& Hummel T (2005) Zinc gluconate in the treatment of dysgeusia - a randomized clinical trial. J Dental Res 84, 35-38.

26. Takeda N, Takaoka T, Ueda C, Toda N, Kalubi B \& Yamamoto $S$ (2004) Zinc deficiency in patients with idiopathic taste impairment with regard to angiotensin converting enzyme activity. Auris Nasus Larynx 31, 425-428.

27. Ripamonti C, Zecca E, Brunelli C, Fulfaro F, Villa S, Balzarini A, Bombardieri E \& de Conno F (1998) A randomised controlled clinical trial to evaluate the effects of zinc sulphate on cancer patients with taste alterations caused by head and neck irradiation. Cancer 82, 1938-1945.

28. Rikkert MGMO \& Rigaud AS (2003) Malnutrition research: high time to change the menu. Age Ageing 32, 241-243.

29. Bloomfield RS, Graham BG, Schiffman SS \& Killenberg PG (1999) Alteration in chemosensory function in end-stage liver disease. Physiol Behav 66, 203-207.

30. McClean CJ, McClain M, Barve S \& Boosalis MG (2002) Trace metals and the elderly. Clin Geriatr Med 18, 801-818.

31. Mojet J, Heidema J \& Christ-Hazelhof E (2003) Taste perception with age: generic or specific losses in supra threshold intensities of five taste qualities. Chem Senses 28, 397-413.

32. Spitzer ME (1988) Taste acuity in institutionalised and noninstitutionalised elderly men. J Gerontol 43, 71-74.

33. Cooper RM, Bilash I \& Zubek JP (1959) The effect of age on taste sensitivity. J Gerontol 14, 56-58.

34. Polito A, Meunier N, Andriollo-Sanchez M, et al. (2005) Screening and recruitment procedure of late-middle aged and older subjects. The Zenith study. Eur J Clin Nutr 59, Suppl. 2, S8-S12.

35. Milne DB, Davis CD \& Nielsen FH (2001) Low dietary zinc alters indices of copper function and status in postmenopausal women. Nutr 17, 701-708

36. Solomons NW (1986) Competitive interaction of iron and zinc in the diet: consequences for human nutrition. J Nutr 116, 927-935.

37. Yesavage JA, Brink TL, Rose TL, Lum O, Huang V, Adey M \& Leirer VO (1983) Development and validation of a geriatric depression screening scale: a preliminary report. J Psychiatr Res 17, 37-49.

38. Folstein MF, Folstein SE \& McHugh PR (1975) Mini Mental State: a practical method for grading the cognitive state of patients for the clinician. J Psychiat Res 12, 189-198.
39. Andriollo-Sanchez M, Hininger-Favier I, Meunier N, et al. (2005) Zinc intake and status in middle-aged and older European Subjects: the Zenith study. Eur J Clin Nutr 59, Suppl. 2, S37-S41.

40. Arnaud J, Bellanger J, Bienvenu F, Chappuis P \& Favier A (1986) Recommended method for assaying serum zinc with flame atomic absorption. Ann Biol Clin 44, 77-87.

41. Schiffman SS \& Graham BG (2000) Taste and smell perception affect appetite and immunity in the elderly. Eur J Clin Nutr 54, Suppl. 3, S54-S63.

42. Bischmann DA \& Witte KL (1996) Food identification, taste complaints, and depression in younger and older adults. Exp Ageing Res 22, 23-32.

43. Green DM \& Swets JA (1966) Signal Detection Theory and Psychophysics. New York: Wiley.

44. O'Mahony M (1972) Salt taste sensitivity: a signal detection approach. Perception 1, 459-464.

45. O'Mahony M (1992) Understanding discrimination tests: a userfriendly treatment of response bias, rating and ranking R-index tests and their relationship to signal detection. J Sens Stud 7, $1-47$.

46. Delwiche J \& O'Mahony M (1996) Flavour discrimination: an extension of the Thurstonian "paradoxes" to the tetrad method. Food Qual Pref 7, 1-5.

47. Goldstein EB (2002) Sensation and Perception, 6th ed. Pacific Grove, CA: Wadsworth-Thomson.

48. Lucas F \& Bellisle F (1987) The measurement of food preferences in humans: do taste and spit tests predict consumption? Physiol Behav 39, 739-743.

49. Brown J (1974) Recognition assessed by rating and ranking. Br J Psychol 65, 13-22.

50. O'Mahony M, Gardner L, Long D, Heintz C, Thompson B \& Davies M (1979) Salt taste detection: an R-index approach to signal-detection measurements. Perception 8, 497-506.

51. McDaid O, Stewart-Knox B, Parr H \& Simpson E (2007) Dietary zinc intake and sex differences in taste acuity in young adults. J Hum Nutr Diet 20, 103-110.

52. Bingham SA, Cassidy A, Cole TJ, et al. (1995) Validation of weighed records and other methods of dietary assessment using the $24 \mathrm{~h}$ urine nitrogen technique and other biological markers. Br J Nutr 73, 531-559.

53. Gibney MJ, MacDonald IA \& Roche HM (2003) Nutrition and Metabolism. Oxford: Blackwell Publishing.

54. Livingstone MBE \& Black AE (2003) Markers of the validity of reported energy intake. J Nutr 133, Suppl. 3, S895-S920.

55. Nelson M, Black AE, Morris JA \& Cole TJ (1989) Between and within subject variation in nutrient intake from infancy to old age: estimating the number of days required to rank dietary intakes with desired precision. Am J Clin Nutr 50, 155-167.

56. Rodriguez-Palmero M, Castellote-Bargallo AI, Lopez-Sabater C, de la Torre-Boronat C \& Rivero-Urgell M (1998) Assessment of dietary nutrient intakes: analysed vs calculated values. Food Chem 61, 215-221.

57. Moon CS, Zhang ZW, Shimbo S, Hokimoto S, Shimazaki K, Saito T, Shimizu A, Imai Y, Watanabe T \& Ikeda M (1996) A comparison of the food composition table-based estimates of dietary element intake with the values obtained by inductively coupled plasma atomic emission spectrometry: an experience in a Japanese population. J Trace Elem Med Biol 10, 237-244.

58. Maret W \& Sandstead HH (2006) Zinc requirements and the risk and benefits of zinc supplementation. J Trace Elem Med Biol 20, 3-18.

59. Ma J \& Betts NM (2000) Zinc and copper intakes and their major food sources for older adults in the 1994-96 Continuing Survey of Food Intakes by Individuals (CSFII). J Nutr 130, 2838-2843. 
60. MacDonald BA, Watts BM \& Fitzpatrick DW (1993) Comparison of taste thresholds in selected Canadian and Peruvian populations. Ecol Food Nutr 30, 241-251.

61. Garrow JS, James WPT \& Ralph A (2000) Human Nutrition and Dietetics, 10th ed. Edinburgh: Churchill Livingstone.

62. Davis CD, Milne DB \& Nielsen FH (2000) Changes in dietary zinc and copper affect zinc status indicators of postmenopausal women, notably, extracellular superoxide dismutase and amyloid precursor proteins. Am J Clin Nutr 71, 781-788.

63. Food and Nutrition Board, Institute of Medicine (2000) Zinc. In Dietary Reference Intakes for Vitamin A, Vitamin K, Arsenic, Boron, Chromium, Copper, Iodine, Iron, Manganese, Molybdenum, Nickel, Silicon, Vanadium, and Zinc, pp. 442-501 Washington, DC: National Academy Press.

64. Briefel RR, Bialostosky K, Kennedy-Stephenson J, McDowell MA \& Wright JD (2000) Zinc intake of the US population: findings from the third National Health and Nutrition Examination Survey, 1988-1994. J Nutr 130, Suppl. 5S, 1367S-1373S.
65. Marshall JA \& Yanik MM (2001) Synthesis of a C1-C21 subunit of the protein phosphatase inhibitor tautomycin: a formal total; synthesis. J Organic Chem 66, 1373-1379.

66. European Commission Scientific Committee on Food (2003) Opinion of the Scientific Committee on Food on the Tolerable Upper Intake Level of Zinc. Brussels: European Commission Health and Consumer Protection Directorate-General.

67. Sandström B (2001) Considerations in estimates of requirements and critical intake of zinc adaptation, availability and interactions. Analyst 120, 913-915.

68. Hininger-Favier I, Andriollo-Sanchez M, Arnaud J, et al. (2007) Age and sex-dependent effects of long-term zinc supplementation on essential trace element status and lipid metabolism in European subjects. The Zenith study. Br J Nutr 97, $569-578$.

69. Ryan-Crowe V (1980) Taste acuity response to zinc supplementation in hemodialysis patients. Dissertation Abstr Int 41, $148-149$. 